\title{
Generalized Formulation for Fatigue Assessment of Laser Stake- welded T-joints Varying Thicknesses and Loading Conditions
}

\author{
Pasquale Gallo ${ }^{1,2 *}$, Heikki Remes $^{2}$, and Jani Romanoff ${ }^{2}$ \\ ${ }^{1}$ Department of Mechanical Engineering and Science, Kyoto University, 615-8540, Japan \\ ${ }^{2}$ Department of Mechanical Engineering, Aalto University, Espoo 02150, Finland
}

\begin{abstract}
The present work considers the evolution of the crack tip plasticity ahead of the crack-like notches with varying the loading condition and the thickness of laser stake-welded T-joints. A general procedure is described for the fatigue assessment of the joints under different loading conditions and made of different thicknesses. The new method is based on the analyses of the first order plastic radius (according to Irwin) for pure mode I, and it is generalized to mixed mode (I+II) by using the Minimum Plastic Zone Radius (MPZR) criterion. The method is validated, in the end, with a case study and explains why the fatigue slope $m$ varies for joints loaded under bending/tension and when the thickness is reduced. The results prove that the procedure gives an excellent estimation of the fatigue life.
\end{abstract}

\section{Introduction}

Research, development, and production of laser stakewelded joints have been pushed and supported by the demand of light and safe structures in different fields. Indeed, weight reduction is a very important aspect. In marine design, for instance, thin sandwich panels have been employed to replace thick plates and reduce the overall weight. The panel consists of thin plates assembled together by using laser welding process and by realizing laser stake-welded T-joints (see Fig. 4). From the first reports published in the late '90s [1-3], laser stake-welded T-joints showed an unexplained difference in fatigue behaviour (slope of the fatigue curve) when the loading condition (tension VS bending) and the thickness of the plates connected (thin VS thick structures) are varied. These results were later found and confirmed by other authors [4-7]. Few studies have tried recently to explain why the slope of the fatigue resistance curve changes with the loading conditions and the thickness of the plate. Fundamental contributions have been provided by Frank and collaborators [8-11] that re-analysed the slope variations by employing a stress gradient defined by the authors, at the crack tip. This parameter showed a higher gradient of elastic stresses in bending than in tension and in thin than thick plates (similar findings were reported in [12]). The stress field analysis ahead of the crack tip also proved that the mixed-mode ratio is strongly influenced by the face plate thickness. Recently, Gallo et al. $[13,14]$ showed that the difference in the fatigue slope of laser stake-welded Tjoints was explained by analysing the stress distribution and plastic zone ahead of the crack tip.

Thus, the short literature review reported above shows that the fatigue strength is affected by the plate thickness and the loading mode. Based on these observations, the method proposed in this work is based on the first-order plastic zone size $r_{\mathrm{y}}$ according to Irwin combined with the Minimum Plastic Zone Radius (MPZR) criterion: two joints with the same $r_{\mathrm{y}}$ in the MPZR direction are compared, and the stress gradient over $r_{\mathrm{y}}$ (along the MPZR direction) is evaluated by finite element (FE) analyses. The first-order plastic zone, indeed, permits a fast evaluation of a so-called crack driving force and a direct comparison of the stress gradient between joints of different geometries and load configurations. The MPZR criterion, instead, permits to evaluate the direction of the crack initiation rapidly and therefore to define the correct orientation under mixedmode (I+II) loading condition. The methods initially formulated by Gallo et al. separately for thick joints (only for tension and bending loads) [13], and later for joints of different thicknesses [14], is reformulated here in a unified formulation that applies indistinctly to all configuration of loads and/or thicknesses. The method is then verified with experiments taken from the literature $[8,9]$.

\section{Analytical frame}

\subsection{Generalized definition of the representative crack driving force ratio}

The quantification of the size of the crack tip yielding zone was first proposed by Irwin in the 1960s [15,16]. He combined a mode I singular stress field (in the crack plane) with a yielding criterion, i.e. $\sigma_{\mathrm{yy}}=\sqrt{ } 3 \sigma_{\mathrm{YS}}$ for plane strain and $\sigma_{\mathrm{yy}}=\sigma_{\mathrm{YS}}$ for plane stress, and assumed an elastic perfectly plastic behaviour of the material. He

Corresponding author: pasquale.gallo@aalto.fi 
then derived the so-called first-order estimation of the plastic zone size $r_{\mathrm{y}}$ (see Fig. 1) and, by simple force balance within the forces $F_{1}$ and $F_{2}$ depicted in Fig. 1b, the second-order estimation of the plastic zone size $r_{\mathrm{p}}$ [17]:

$r_{y}=\frac{1}{6 \pi}\left(\frac{K_{I}}{\sigma_{Y S}}\right)^{2}, \quad r_{p}=\frac{1}{3 \pi}\left(\frac{K_{I}}{\sigma_{Y S}}\right)^{2}$ plane strain

$r_{y}=\frac{1}{2 \pi}\left(\frac{K_{I}}{\sigma_{Y S}}\right)^{2}, \quad r_{p}=\frac{1}{\pi}\left(\frac{K_{I}}{\sigma_{Y S}}\right)^{2}$ plane stress

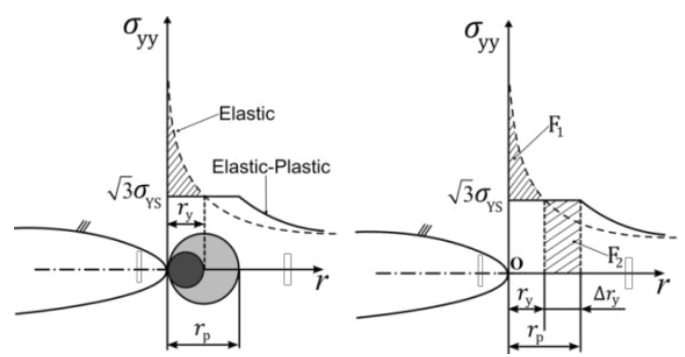

Fig. 1. a) Example of the first-order $r_{y}$ and second-order $r_{p}$ plastic radius, and b) stress redistribution and force equilibrium; plane strain.

In the method proposed in the present work, same first-order plastic radius $r_{\mathrm{y}}$ along $\theta_{0}$, as depicted in Fig. 2, is assumed as a condition to compare two joints. The force $F_{1}$ depicted in Fig. 2 is assumed as the crack driving force, and can be used to quantify the stress gradient variation between joints of different loading conditions or thicknesses $[13,14]$.



Fig. 2. Schematic representation of the crack driving force $F_{1}$ and first-order plastic zone size $r_{y}$ in the MPZR direction.

The crack initiation angle $\theta_{0}$ is evaluated by using the Minimum Plastic Zone Radius (MPZR) criterion and defined as the minimum distance to the crack tip, i.e., in the direction of a relative MPZR where the circumferential stress is tensile according to Refs. $[14,18,19]$. The elastic-plastic boundary, instead, is defined according to the von Mises yield criterion. It is verified in [14] that the crack initiation angle $\theta_{0}$ that is obtained is close to the direction reported experimentally in the literature [11]. Being the plastic shape affected by the loading modes, the crack driving force evaluated over $r_{\mathrm{y}}$, but in the $\theta_{0}$ direction (see Fig. 2), permits the implicit consideration of the mixed-mode effect. Table 1 lists the values of $\theta_{0}$ for different face plate thicknesses. Theoretically, $\theta_{0}$ can be obtained by minimizing the equation of the elastic-plastic boundary (radius of the core region) $r$ of Eq. (4), i.e.:

$$
\begin{aligned}
& \left(\frac{\partial r}{\partial \theta}\right)_{\theta=\theta_{0}}=0, \quad\left(\frac{\partial^{2} r}{\partial \theta^{2}}\right)_{\theta=\theta_{0}}>0 \\
& r=\frac{1}{2 \pi \sigma_{\text {IS }}^{2}}\left[K_{l}^{2} \cos ^{2} \frac{\theta}{2}\left\{\kappa^{2}+3 \sin ^{2} \frac{\theta}{2}\right\}+K_{l} K_{I I} \sin \theta\{3 \cos \theta-\kappa\}+K_{I I}^{2}\left\{3+\sin ^{2} \frac{\theta}{2}\left(\kappa^{2}-9 \cos ^{2} \frac{\theta}{2}\right)\right\}\right] \\
& \kappa=1-2 v \quad \text { For plane strain } \\
& \kappa=1 \quad \text { For plane stress }
\end{aligned}
$$

Table 1. Mixed-mode ratios achieved and crack initiation direction (see Figures 2 and 4).

\begin{tabular}{|c|c|c|}
\hline Specimen & $\begin{array}{c}\boldsymbol{\theta}_{\mathbf{0}} \\
(\mathbf{d e g})\end{array}$ & $\begin{array}{c}\boldsymbol{\theta}_{\mathbf{0}} \text { exp. [11] } \\
(\mathbf{d e g})\end{array}$ \\
\hline$t_{\mathrm{f}}=2.5 \mathrm{~mm}$ & 55 & $45-50$ \\
\hline$t_{\mathrm{f}}=8 \mathrm{~mm}$ & 20 & 30 \\
\hline$t_{\mathrm{f}}=16 \mathrm{~mm}$ & 7 & - \\
\hline
\end{tabular}

The crack driving force is theoretically defined as assuming a plane strain condition by the following integral:

$$
F_{1}=\int_{0}^{r_{y}} \sigma_{\theta \theta} \mathrm{dr}-\sqrt{3} \sigma_{Y S} \cdot r_{y}
$$

where $\sigma_{\theta \theta}$ is the generic tensile elastic stress distribution, in polar coordinates. For pure mode I and large thicknesses, the angle $\theta_{0}$ becomes 0 . The ratio between the force $F_{1}$ of two generic joints $A$ and $b$, assuming the same $r_{\mathrm{y}}$ along the MPZR direction, is defined as the representative crack driving force ratio, $F_{\mathrm{R}}$ :

$$
F_{R}=\frac{F_{1 \mathrm{~b}}}{F_{1 \mathrm{~A}}}
$$

The crack driving force ratio is then used as a correction parameter to define an effective $J$-integral $\sqrt{ } \mathrm{J}_{\text {eff }}$ in the next section.

The definition above, based on Irwin's monotonic plastic zone, neglects any contribution of the cyclic plasticity. However, the reversed plastic zone is approximately $1 / 4$ of the size of the monotonic plastic zone and therefore very small in the cases considered here. Additionally, its contribution to high fatigue load levels becomes even less relevant [21].

\subsection{Estimation model}

The present authors assume that the fatigue curve of two generic joints with different fatigue slopes can be derived from each other if the slope effect due to the stress gradient is considered through the crack driving force ratio $F_{\mathrm{R}}$. On the basis of these assumptions, the fatigue curves of two generic series of joints $(A$ and $b$ ), in terms of the square root of the J-Integral, are defined by these Wöhler equations $[8,10]$ (for load ratio $\mathrm{R}=0$ ):

$$
\begin{aligned}
& (\sqrt{J})^{m_{A}} \cdot N_{f, A}=C_{A} \\
& (\sqrt{J})^{m_{b}} \cdot N_{f, b}=C_{b}
\end{aligned}
$$


Where $\sqrt{\mathbf{J}}$ is a generic load, $m$ is the slope of the curve, $N_{\mathrm{f}}$ is the number of cycles to failure, and $C$ is a constant. In order to take into account the slope effect and the relationship between the fatigue resistance curves, the fatigue curve of an arbitrary joint $b$ is expressed as a function of the parameters of the curves of the joints $A$ through the effective J-integral, defined as follows [13]:

$$
\sqrt{J}_{\text {eff }}=\sqrt{J} \cdot F_{R}
$$

As a consequence, Eq. (8) is rewritten as follows:

$$
\left(\sqrt{J}_{e f f}\right)^{m_{A}} \cdot N_{f, b}=C_{A}
$$

The equation shows that if the effective $\mathrm{J}$-integral is employed in the fatigue curve of the generic joints $A$, the number of cycles to failure of the joints $b$ is easily derived.

On the basis of the $F_{\mathrm{R}}$ concept introduced earlier, the following procedure can be used to derive the number of cycles to failure of the considered joints $[13,14]$ :

1. At first, the crack initiation direction, $\theta_{0, \mathrm{~A}}$ for joint type $A$ and $\theta_{0, \mathrm{~b}}$ for joints type $b$, should be derived by using finite element analysis and according to the MPZR criterion;

2. once the desired $\sqrt{\mathbf{J}}$ is selected, the corresponding force $F_{1 \mathrm{~A}}$ and first-order plastic radius $r_{\mathrm{y}}$ in the $\theta_{0, \mathrm{~A}}$ direction (see Fig. 2) should be calculated through finite element analysis; $\theta_{0, \mathrm{~A}}$ tends to 0 for large thicknesses under tension loads;

3. through finite element analysis, evaluation of the equivalent force $F_{1 \mathrm{~b}}$ for the joints of type $b$ in the $\theta_{0, \mathrm{~b}}$ direction, assuming the same firstorder plastic radius as evaluated in the previous step (the external load is determined by trial and error until the target $r_{\mathrm{y}}$ is obtained);

4. evaluation of $F_{\mathrm{R}}$ as defined by Eq. (6);

5. evaluation of the effective $\sqrt{\mathrm{J}_{\text {eff }}}$ according to Eq. (9);

6. the new effective J-Integral is then used as the input parameter in the fatigue curve equation of the joints $A$ and the number of cycles to failure of the joints $b$ is obtained; Eq. (10).

A simple diagram summarizing the procedure is proposed in Fig. 3.

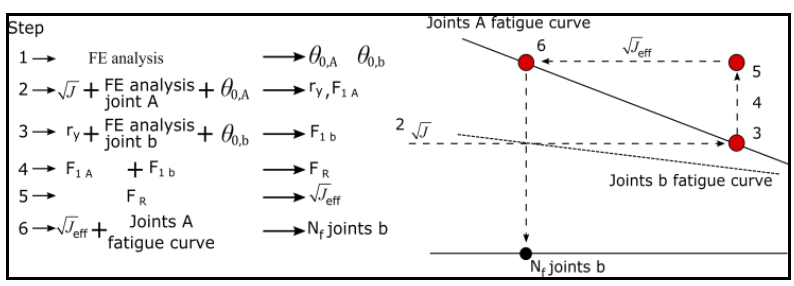

Fig. 3. Diagram of the procedure proposed for the determination of the number of cycles to failure, $\mathrm{R}=0$.

The procedure is valid until the crossing point/endurance limit of the two curves is reached (i.e., two million cycles) after which run-out specimens were obtained for all the considered joints [8,11]. Indeed, the difference in the plasticity at the crack tip of two joints vanishes at the endurance limit. As a consequence, the difference between the crack driving forces becomes also negligible.

\section{Case study}

The model is verified against data taken from [8]. Two configurations have been considered: (i) Joints loaded under tension were compared to joints loaded under bending by keeping the same geometry $\left(t_{f}=8 \mathrm{~mm}, t_{w}=8\right.$ mm, see Table 2 and Fig. 4); (ii) The joints were loaded only under tension and the thicknesses were varied. The selected geometries are represented in Fig. 4 and listed in Table 2. The mechanical properties are the same for all the considered joints: $\mathrm{E}=206 \mathrm{GPa}, \sigma_{\mathrm{YS}}=235 \mathrm{MPa}, \sigma_{\mathrm{UTS}}$ $=400 \mathrm{MPa}$.

The joints were modeled by means of the ANSYS ${ }^{\circledR}$ APDL15.0 finite element software package and several numerical simulations under linear elastic conditions were carried out. The 2D 8-node element type PLANE183 was employed with unit thickness, while plane strain condition was assumed. Mechanical properties are reported in Table 2 . With respect to a real $\mathrm{T}$-joint, the symmetry along the web plate axis was assumed, and the web-face gap was neglected since being on average only $9 \mu \mathrm{m}$ [8]. In addition, the contact and the gap between the crack surfaces are not modeled since the very low effect on the final results as observed in $[4,22]$. Several FE simulations were carried and are listed in Table 3 and 4 together with the corresponding numerical J-integrals. These are in agreement with the theoretical elastic J-integrals [23,24].

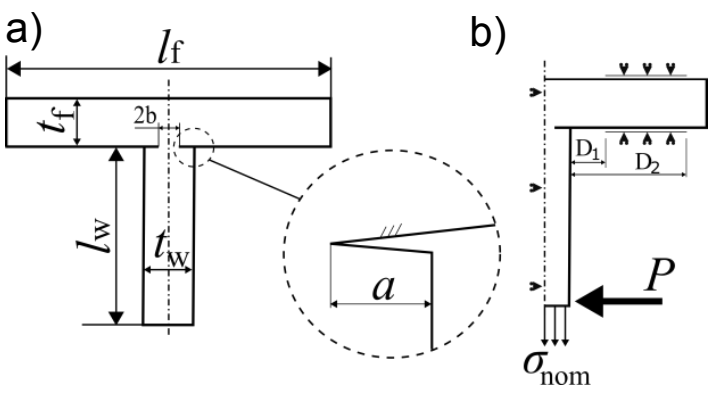

Fig. 4. Case study: a) laser stake-welded T-joint geometry and b) example of the application of constraints and loads.

Table 2. Mechanical properties and geometry of the joints. $\sigma_{\mathrm{YS}}=235 \mathrm{MPa}, \sigma_{\mathrm{UTS}}=400 \mathrm{MPa}, \mathrm{E}=206 \mathrm{GPa}$.

\begin{tabular}{|c|c|c|c|c|c|c|}
\hline $\begin{array}{c}\boldsymbol{t}_{\boldsymbol{f}} \\
\mathbf{m m}\end{array}$ & $\begin{array}{c}\boldsymbol{l}_{f} \\
\mathbf{m m}\end{array}$ & $\begin{array}{c}\boldsymbol{t}_{w} \\
\mathbf{m m}\end{array}$ & $\begin{array}{c}\boldsymbol{l}_{w} \\
\mathbf{m m}\end{array}$ & $\begin{array}{c}\boldsymbol{a} \\
\mathbf{m m}\end{array}$ & $\begin{array}{c}\mathbf{D}_{\mathbf{1}} \\
\mathbf{m m}\end{array}$ & $\begin{array}{c}\mathbf{D}_{2} \\
\mathbf{m m}\end{array}$ \\
\hline 2.5 & 100 & 4 & 60 & 1.27 & 4.8 & 44 \\
\hline 8 & 100 & 8 & 60 & 2.50 & 3.2 & 44 \\
\hline 16 & 100 & 14 & 60 & 4.25 & 0 & 44 \\
\hline
\end{tabular}


Table 3. Load levels, corresponding numerical J-integral and applied nominal loads for the joint loaded under tension and bending ( $t_{f}=8 \mathrm{~mm}, t_{w}=8 \mathrm{~mm}$, see Table 2$) ; \sigma_{\text {nom }}$ refers to the gross area.

\begin{tabular}{|c|c|c|c|c|c|}
\hline $\begin{array}{c}\text { Load } \\
\text { Level }\end{array}$ & $\begin{array}{c}\boldsymbol{r}_{\mathbf{y}} \\
\mathbf{m m}\end{array}$ & $\begin{array}{c}\mathbf{J} \text { tension } \\
\mathbf{k J} / \mathbf{m}^{\mathbf{2}}\end{array}$ & $\begin{array}{c}\mathbf{J} \text { bending } \\
\mathbf{k J} / \mathbf{m}^{\mathbf{2}}\end{array}$ & $\begin{array}{c}\boldsymbol{\sigma}_{\text {nom }} \\
\mathbf{M P a}\end{array}$ & $\begin{array}{c}\mathbf{P} \\
\mathbf{N} / \mathbf{m m}\end{array}$ \\
\hline 1 & 0.010 & 0.0159 & 0.0163 & 16.875 & 1.65 \\
\hline 2 & 0.075 & 0.1133 & 0.1269 & 45 & 4.60 \\
\hline 3 & 0.152 & 0.2141 & 0.2733 & 61.875 & 6.75 \\
\hline 4 & 0.231 & 0.3146 & 0.4711 & 75 & 8.75 \\
\hline 5 & 0.306 & 0.4053 & 0.6996 & 85.125 & 10.80 \\
\hline
\end{tabular}

Table 4. Tension loads applied to the joints with thicknesses variation; $\sigma_{\text {nom,net }}$ refers to the actual cross-section area of the weld (2b in Fig. 4).

\begin{tabular}{|c|c|c|c|c|c|c|c|}
\hline \multirow{3}{*}{$\begin{array}{l}\text { Load } \\
\text { Level }\end{array}$} & \multirow{3}{*}{$\begin{array}{c}r_{\mathbf{y}} \\
\mathbf{m m}\end{array}$} & \multicolumn{2}{|c|}{$t_{\mathrm{f}}=2.5 \mathrm{~mm}$} & \multicolumn{2}{|c|}{$t_{\mathrm{f}}=8 \mathrm{~mm}$} & \multicolumn{2}{|c|}{$t_{\mathrm{f}}=16 \mathrm{~mm}$} \\
\hline & & $\mathbf{J}$ & $\sigma_{\text {nom,net }}$ & $\mathbf{J}$ & $\sigma_{\text {nom,net }}$ & $\mathbf{J}$ & $\sigma_{\text {nom,net }}$ \\
\hline & & $\mathrm{kJ} / \mathrm{m}^{2}$ & $\mathrm{~kJ} / \mathrm{m}^{2}$ & $\mathrm{~kJ} / \mathrm{m}^{2}$ & MPa & MPa & MPa \\
\hline 1 & 0.051 & 0.1647 & 136 & 0.2171 & 154 & 0.2309 & 153 \\
\hline 2 & 0.082 & 0.2752 & 175 & 0.3481 & 195 & 0.3682 & 193 \\
\hline 3 & 0.104 & 0.3600 & 201 & 0.4431 & 220 & 0.4739 & 219 \\
\hline 4 & 0.135 & 0.4862 & 233 & 0.5721 & 250 & 0.6091 & 249 \\
\hline 5 & 0.171 & 0.6414 & 268 & 0.7177 & 280 & 0.7568 & 277 \\
\hline
\end{tabular}

\section{Results and discussion}

\subsection{Joints loaded under tension and bending}

Table 5 summarizes the results by comparing the estimated and experimental [8] number of cycles to failure of the joints under bending loads. The method gives an excellent estimation with a maximum discrepancy of $16 \%$.

Table 5. Comparison between estimated and expected number of cycles to failure for bending load. * fatigue slope $m=4.2 ; * *$ fatigue slope $m=7$; fatigue strength at two million cycles is $0.37 \mathrm{~kJ}^{0.5} / \mathrm{m}$ for all the curves [8].

\begin{tabular}{|c|c|c|c|c|c|c|}
\hline $\begin{array}{c}\text { Load } \\
\text { Level }\end{array}$ & $\boldsymbol{F}_{\mathbf{R}}$ ratio & $\sqrt{ } \mathbf{J}$ & $\sqrt{ } \mathbf{J}_{\text {eff }}$ & $\mathbf{N}_{\mathbf{f} \text { bending }}$ & $\mathbf{N}_{\mathbf{f} \text { bending }}$ & $\Delta \%$ \\
\hline bend./ten. & $\mathbf{k} \mathbf{J}^{\mathbf{0 . 5}} / \mathbf{m}$ & $\mathbf{k} \mathbf{J}^{\mathbf{0 . 5}} / \mathbf{m}$ & $\mathbf{E s t i m}$ ** & $\mathbf{E x p . * * *}$ & \\
\hline 1 & 1 & 0.1263 & 0.1263 & $>2.00 \mathrm{E}+06$ & $>2.00 \mathrm{E}+06$ & - \\
\hline 2 & $1.07 \approx 1$ & 0.3365 & 0.3365 & $>2.00 \mathrm{E}+06$ & $>2.00 \mathrm{E}+06$ & - \\
\hline 3 & 1.17 & 0.4627 & 0.5417 & $4.04 \mathrm{E}+05$ & $4.18 \mathrm{E}+05$ & $-3 \%$ \\
\hline 4 & 1.28 & 0.5609 & 0.7179 & $1.24 \mathrm{E}+05$ & $1.09 \mathrm{E}+05$ & $14 \%$ \\
\hline 5 & 1.39 & 0.6366 & 0.8827 & $5.19 \mathrm{E}+04$ & $4.48 \mathrm{E}+04$ & $16 \%$ \\
\hline
\end{tabular}

\subsection{Joints loaded under tension with a variation of the thickness}

Table 6 and Table 7 compares the estimated and experimental [8] number of cycles to failure of joints of different thicknesses. The maximum discrepancy is only $19 \%$ and therefore the results are in good agreement with experiments.

Table 6. Estimated and expected number of cycles to failure for thin joints, evaluated from FE analyses of the thick joints $t_{\mathrm{f}}$ $=8 \mathrm{~mm} ; F_{\mathrm{R}}=F_{1 \mathrm{tf}=2.5 \mathrm{~mm}} / F_{1 \mathrm{tf}=8 \mathrm{~mm}}$.

\begin{tabular}{|c|c|c|c|c|c|c|}
\hline $\begin{array}{c}\text { Load } \\
\text { Level } \\
t_{\mathrm{f}}=8 \mathrm{~mm}\end{array}$ & $F_{\mathrm{R}}$ & $\begin{array}{c}\sqrt{ } \mathbf{J} \\
\mathbf{k J} / \mathbf{m}^{2}\end{array}$ & $\begin{array}{r}\sqrt{ } \mathbf{J}_{\text {eff }} \\
\mathbf{k J} / \mathbf{m}^{2}\end{array}$ & $\begin{array}{c}N_{\mathrm{f}} \text { estimated } \\
t_{\mathrm{f}}=2.5 \mathrm{~mm}\end{array}$ & $\begin{array}{c}\mathrm{N}_{\mathrm{f}} \exp \\
t_{\mathrm{f}}=2.5 \mathrm{~mm}\end{array}$ & $\Delta \%$ \\
\hline 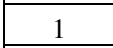 & 03 & 0.4659 & 0.4813 & & & -1 \\
\hline 2 & 1.066 & 0.5900 & 6289 & & 2.78 & $-2 \%$ \\
\hline 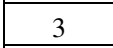 & 086 & 656 & 28 & & 1.671 & $-3 \%$ \\
\hline 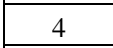 & .121 & 0.7564 & 0.8477 & & $9.71 \mathrm{E}+04$ & $-9 \%$ \\
\hline & & 8472 & 0.9822 & $5.09 \mathrm{E}+04$ & $6.01 \mathrm{E}+04$ & $-15 c$ \\
\hline
\end{tabular}

Table 7. Estimated and expected number of cycles to failure for the thin joints evaluated from $\mathrm{FE}$ analysis of the thick joints $t_{\mathrm{f}}=16 \mathrm{~mm} ; F_{\mathrm{R}}=F_{1 \mathrm{tf}=2.5 \mathrm{~mm}} / F_{1 \mathrm{tf}=16 \mathrm{~mm}}$.

\begin{tabular}{|c|c|c|c|c|c|c|}
\hline $\begin{array}{c}\text { Load } \\
\text { Level } \\
t_{\mathrm{f}}=16 \mathrm{~mm}\end{array}$ & $F_{\mathrm{R}}$ & $\begin{array}{c}\sqrt{ } \mathbf{J} \\
\mathbf{k J} / \mathbf{m}^{2}\end{array}$ & $\begin{array}{c}\sqrt{ } \mathbf{J}_{\text {eff }} \\
\mathbf{k J} / \mathbf{m}^{2}\end{array}$ & $\begin{array}{c}N_{\mathrm{f}} \text { estimated } \\
t_{\mathrm{f}}=2.5 \mathrm{~mm}\end{array}$ & $\begin{array}{c}\mathrm{N}_{\mathrm{f}} \exp \\
t_{\mathrm{f}}=2.5 \mathrm{~mm}\end{array}$ & $\Delta \%$ \\
\hline 1 & 1.043 & 0.4815 & 0.5020 & $6.35 \mathrm{E}+05$ & $6.57 \mathrm{E}+05$ & $-3 \%$ \\
\hline 2 & 1.077 & 0.6087 & 0.6557 & $2.33 \mathrm{E}+05$ & $2.44 \mathrm{E}+05$ & $-4 \%$ \\
\hline 3 & 1.097 & 0.6862 & 0.7531 & $1.38 \mathrm{E}+05$ & $1.47 \mathrm{E}+05$ & $-6 \%$ \\
\hline 4 & 1.134 & 0.7789 & 0.8830 & $7.60 \mathrm{E}+04$ & $8.58 \mathrm{E}+04$ & $-11 \%$ \\
\hline 5 & 1.178 & 0.8700 & 1.0246 & $4.34 \mathrm{E}+04$ & $5.38 \mathrm{E}+04$ & $-19 \%$ \\
\hline
\end{tabular}

\subsection{Slopes variations}

By considering the joints with different thicknesses as an example, the more significant crack driving force $F_{1}$ of the thin joints generates a higher level of damage in the representative fatigue volume, which results in a lower number of cycles to failure. The physical meaning of this statement is shown in Fig. 5. The label 1 represents a high number of cycles (low load levels), while the label 2 represents the low number of cycles situation (high load levels). In case 1, approaching the fatigue limit, the thin and thick joints have the same stress redistribution; for the case 2 , the crack driving force $F_{1}$ of the thin plates $\left(F_{1, \mathrm{t}}\right.$ blu area $)$ is higher than the thick case $\left(F_{1, \mathrm{~T}}\right.$ black area). Same identical comments can be made if joints loaded under tension and bending are compared instead. Therefore, for a chosen number of cycles to failure, this phenomenon is considered by a lower value of $\sqrt{ } \mathrm{J}$ for the thin joints needed to generate the same amount of damage. The parameter $F_{\mathrm{R}}$ defined by Eq. (6) estimates correctly the ratio within $\sqrt{J}$ for the thin and thick joints and for the bending and tension joints, at the same number of cycles to failure. This gives the possibility to evaluate the number of cycle to failure of thin plates on the basis of the thick joints fatigue curve (more easy to obtain experimentally). Similarly, joints loaded under bending can be assessed by considering the fatigue curve of the joints loaded under tension. 

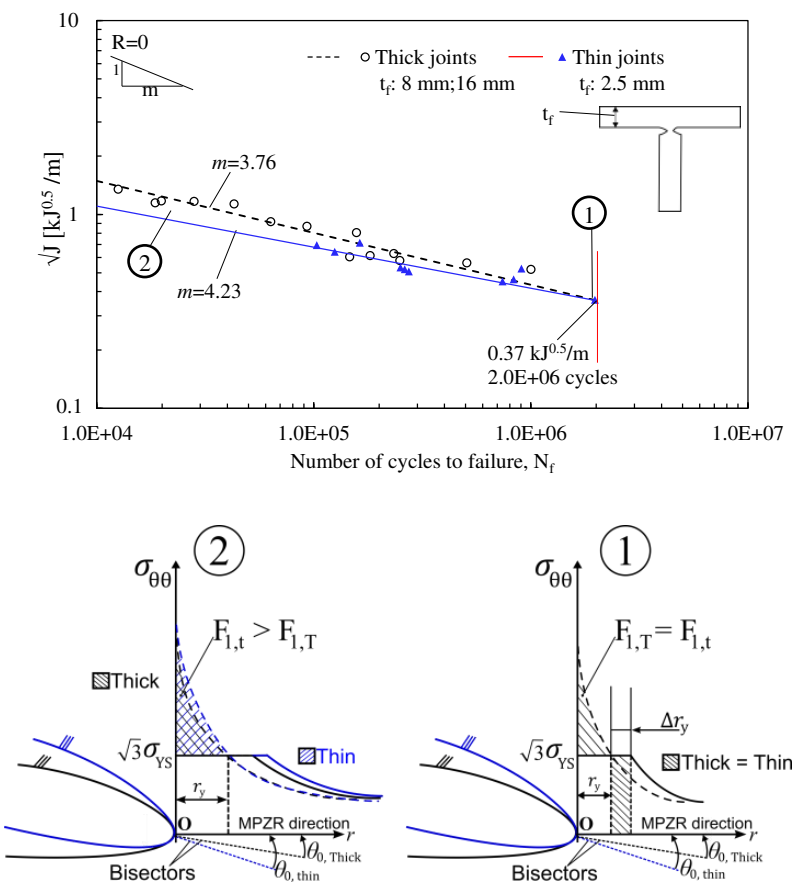

Fig. 5. High load-level (2) and low load-level (1) crack driving force, and matching with fatigue curves taken from [8]; the subscript $T$ stands for thick, $t$ stands for thin.

The results show, in addition, that the plastic radius develops faster for the thin joints than for the thick joints and therefore the first order plastic radius in the MPZR direction is subjected to a bigger crack driving force. Fig. 6 reproduces an example of the plastic radius of the thin joints for the highest load levels (therefore the worst scenario with the largest plastic zone). The picture has been realized by keeping real ratio between dimensions and it gives an idea of the size of the plastic radius compared to the thicknesses involved. The figure proves that the plastic radius is effectively rotated $(55 \mathrm{deg})$, and that its size is relatively small compared to the thicknesses. This result additionally confirms that the Irwin's approach is reasonable since small scale yielding condition is verified. Same results are obtained when thick joints loaded under tension and bending are considered. With the difference that the plastic ratio has a smaller or negligible rotation.

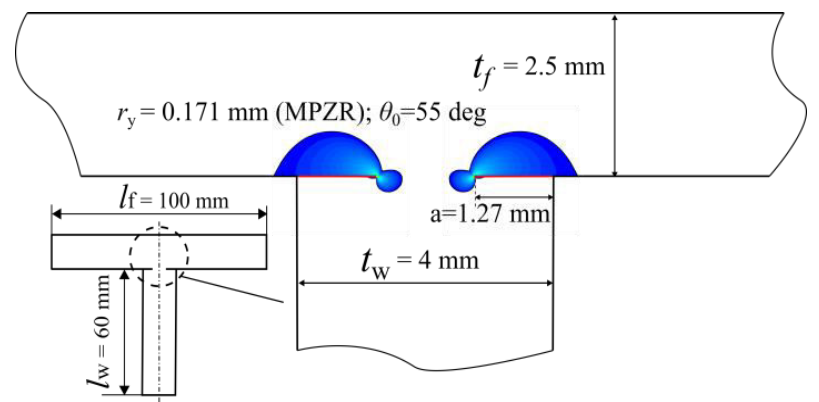

Fig. 6. Representation of the largest plastic radius for the thin joints loaded under tension (load level 5 in Table 4).

\section{Conclusions}

The influence of local plasticity due to thickness variation and loading conditions on the fatigue behaviour of laser stake-welded $\mathrm{T}$-joints was investigated in this contribution. A generalized new model for the fatigue life estimation was also presented.

The results show that the difference in the slope of the fatigue resistance curve is related to the stress gradient at the crack tip. By considering this effect, the proposed model permits to evaluate the number of cycles to failure of the "thin" joints from the fatigue curve of the "thick" joints. Similarly, the method permits to evaluate the number of cycles to failure of the joints loaded under bending from the fatigue curve of the joints loaded under tension. The results are all verified with experimental evidence. The method presents clear limitation when the fatigue mechanisms are not related to the stress gradient, or when the stress gradient effect is too low to be meaningful. In those cases, the specific fatigue mechanisms should be correctly identified and analytical/numerical methods applied coherently. Nevertheless, it is interesting to note that for laser welds, especially of reduced thickness, the gradient effect seems to be always relevant (as summarised in the introduction).

As a future development, a more precise characterization of the plasticity at the crack tip should be carried out experimentally; in addition, new experiments considering other thicknesses and loading conditions would be relevant.

\section{References}

1. G. Socha, K. Koli, P. Kujala, Mechanical Tests and Metallurgical Investigation on Weld Samples, (1998).

2. D. Boronski, J. Szala, Polish Marit. Res. (2006) 31-36.

3. D. Boronski, J. Szala, Polish Marit. Res. (2006) 27-30.

4. W. Fricke, C. Robert, R. Peters, A. Sumpf, Weld. World. 60 (2016) 593-604.

5. Sandwich Consortium, Balance User Group Report No. 3, (2002).

6. A.T. Karttunen, M. Kanerva, D. Frank, J. Romanoff, H. Remes, J. Jelovica, S. Bossuyt, E. Sarlin, Mater. Des. 115 (2017) 64-72.

7. J. Kozak, Polish Marit. Res. S 1 (2006) 13-16.

8. D. Frank, H. Remes, J. Romanoff, Fatigue Fract. Eng. Mater. Struct. 36 (2013) 1336-1351.

9. D. Frank, Int. J. Fatigue. 73 (2015) 77-87.

10. D. Frank, H. Remes, J. Romanoff, Int. J. Fatigue. 33 (2011) 102-114.

11. D. Frank, H. Remes, J. Romanoff, Int. J. Fatigue. 47 (2013) 340-350.

12. P. Lazzarin, F. Berto, Fatigue Fract. Eng. Mater. Struct. 31 (2008) 95-107.

13. P. Gallo, H. Remes, J. Romanoff, Int. J. Fatigue. 99 (2017) 125-136.

14. P. Gallo, M. Guglielmo, J. Romanoff, H. Remes, 
Int. J. Mech. Sci. 136 (2018) 112-123.

15. G.R.R. Irwin, in: Proc. Seventh Sagamore Ordnance Mater. Conf. 4, (1960) 63-78.

16. G.R.R. Irwin, Eng. Fract. Mech. 1 (1968) 241-257.

17. T.L. Anderson, Fracture Mechanics: Fundamentals and Applications, Third Edition, (Taylor \& Francis, 2005).

18. B. Wasiluk, K. Golos, Fatigue Fract. Eng. Mater. Struct. 23 (2000) 381-386.

19. K. Golos, B. Wasiluk, Int. J. Fract. 102 (2000) 341-353.

20. L.P. Pook, Eng. Fract. Mech. 3 (1971).

21. M. Janssen, J. Zuidema, R. Wanhill, Fracture Mechanics, II, (CRC Press, 2004).

22. W. Sundermeyer, W. Fricke, H. Paetzold, Anal. Des. Mar. Struct. V. (2015) 309-315.

23. J.W. Hutchinson, J. Mech. Phys. Solids. 16 (1968) 337-342.

24. J. Rice, J. Appl. Mech. 35 (1968) 379-386. 